\title{
The impact of African ethnicity and migration on pregnancy in women living with HIV in the UK: design and methods
}

\author{
Shema Tariq ${ }^{1 *}$, Alex Pillen ${ }^{2}$, Pat A Tookey ${ }^{3}$, Alison E Brown ${ }^{4}$ and Jonathan Elford ${ }^{1}$
}

\begin{abstract}
Background: The number of reported pregnancies in women with diagnosed HIV in the UK increased from 80 in 1990 to over 1400 in 2010; the majority were among women born in sub-Saharan Africa. There is a paucity of research on how social adversity impacts upon pregnancy in HIV positive women in the UK; furthermore, little is known about important outcomes such as treatment uptake and return for follow-up after pregnancy. The aim of this study was to examine pregnancy in African women living with HIV in the UK.

Methods and design: This was a two phase mixed methods study. The first phase involved analysis of data on approximately 12,000 pregnancies occurring between 2000 and 2010 reported to the UK's National Study of HIV in Pregnancy and Childhood (NSHPC). The second phase was based in London and comprised: (i) semi-structured interviews with 23 pregnant African women living with HIV, 4 health care professionals and 2 voluntary sector workers; (ii) approximately 90 hours of ethnographic fieldwork in an HIV charity; and (iii) approximately 40 hours of ethnographic fieldwork in a Pentecostal church.

Discussion: We have developed an innovative methodology utilising epidemiological and anthropological methods to explore pregnancy in African women living with HIV in the UK. The data collected in this mixed methods study are currently being analysed and will facilitate the development of appropriate services for this group.
\end{abstract}

Keywords: HIV, Pregnancy, Migrants, Ethnicity, Mixed methods research

\section{Background}

\section{HIV infection in the UK}

In 2010 , an estimated 91,500 people were living with HIV in the United Kingdom (UK) [1]; the number continues to grow, mainly due to increased life expectancy as a result of antiretroviral therapy (ART) $[i b i d]$. In the UK, HIV prevalence is elevated both among men who have sex with men (MSM) and African-born heterosexual men and women [1]; for both groups, $5 \%$ are estimated to be living with HIV [ibid]. Within the UK itself there is substantial geographical variation in diagnosed HIV prevalence: 54 local authorities have a diagnosed HIV prevalence of greater than 2 per 1000 population

\footnotetext{
* Correspondence: shema.tariq.2@city.ac.uk

'School of Health Sciences, City University London, 20 Bartholomew Close, London EC1A 7QN, United Kingdom

Full list of author information is available at the end of the article
}

aged $15-59$ years; 29 of these local authorities are in London [1].

\section{HIV in African communities in the UK}

There were an estimated 29,200 people born in Africa living with HIV in the UK by the end of 2010, 66\% $(n=19,300)$ of whom were women [1]. The majority of Africans newly diagnosed with HIV in the UK originate from East Africa, although the epidemic has become more diverse over time. The proportion of Africans diagnosed with HIV who are from East Africa has fallen from just under $75 \%$ in 2001 to approximately $50 \%$ in 2010, whilst in the same time period there was a significant increase in diagnoses in West Africans to a point in 2010 when almost 1 in 3 Africans diagnosed with HIV in the UK were West African (Meaghan Kall, Health Protection Agency, personal communication, 25 June 2012).

\section{Ciomed Central}


Studies have shown that African patients are more likely to present to medical services at a later stage of HIV infection, with advanced disease and greater immune suppression $[1,2]$. This is due to a number of factors including lack of perceived risk, fear of stigma and discrimination, lack of HIV testing in general medical settings, and anxieties regarding medical bills for HIV care $[3,4]$. African heterosexual patients are also more likely to be lost to follow-up from medical care than white MSM [5,6].

Many Africans living with HIV in the UK have a high level of social need $[7,8]$ including financial difficulty [7], social isolation [9] and insecure immigration status $[10,11]$. These are likely to impact on patients' access to healthcare.

\section{HIV and pregnancy in the UK}

There has been a substantial increase in the number of HIV-infected women reported as pregnant to the NSHPC, the UK and Ireland's national surveillance programme for HIV in pregnancy and childhood: a 17fold increase from 82 in 1990 to over 1400 a year since 2006 [12] , with approximately $80 \%$ of pregnancies reported in recent years in women born in Sub-Saharan Africa [13].

The combination of a routine offer of antenatal HIV screening to all pregnant women, use of ART for the prevention of mother-to-child transmission (MTCT), planned mode of delivery and advice to avoid breastfeeding has resulted in a decline in national MTCT rates from approximately $20 \%$ in diagnosed women in 1990 [14] to $1.0 \%$ in $2000-2006$ [15]. The rate is even lower $(0.8 \%)$ in women who have received at least 14 days of antiretroviral therapy prior to delivery [15].

In the UK, there is a paucity of data on antenatal and postnatal outcomes other than mother-to-child transmission and gestational age at delivery. Rates of virological suppression in pregnancy have been estimated at between 67 to 75\% [16-18]. Looking at access to health services, a small study in London demonstrated that up to $65 \%$ of mothers living with HIV failed to return for HIV care after delivery [19]. In terms of care prior to delivery, no studies in the UK examining antenatal care access in HIV-infected women have been identified. Furthermore, there is little work specifically focusing on pregnancy in African women living with HIV in the UK, despite this being the largest group.

Qualitative studies have an important role in elucidating reasons for disparity in outcomes and access, and have provided insights into the experiences of pregnant women living with HIV. However, the vast body of qualitative work on pregnancy and HIV has been conducted in North America and Sub-Saharan Africa and may not be applicable in the UK. Few qualitative studies have explored the experience of pregnancy in women living with HIV in the UK, but those which have [20-22] demonstrated high levels of social isolation and stigma in pregnant women living with HIV. These studies highlighted women's pervasive fear of transmitting HIV to their child and their acceptance of interventions to prevent this, but also revealed the difficulties that accompany these interventions. Two of these studies included African participants, although sample sizes were small and they remain unpublished [20,21]. Wilson's Glasgow-based study [22] was larger but the participants were exclusively white British, presenting difficulties in extrapolating results to an ethnically diverse clinic population.

\section{Rationale for this study}

Few studies have explored the impact of African ethnicity and migration on pregnancy in women living with HIV [15,20,21,23-26]. This is a complex area of study requiring a range of investigatory approaches. We believe that there is an urgent need for large-scale work, both quantitative and qualitative, exploring the multi-faceted relationship between HIV and pregnancy among African migrant women in the UK.

\section{Study objectives}

This study aimed to examine disparities in clinical outcomes and access to services among pregnant African women living with HIV in the UK, and to explore how their experiences of pregnancy may contribute to any identified disparities. For the purposes of this study African was defined as being of black ethnicity and having been born in sub-Saharan Africa. Women of mixed, white or Asian ethnicities who were born in sun-Saharan Africa were not defined as African.

The primary objectives were to:

- explore the association of: (i) ethnicity, (ii) African region of birth, and (iii) duration of residence in the UK with:

- Time of antenatal booking in women living with HIV

- Maternal uptake of antiretroviral therapy

- Detectable maternal HIV viral load at delivery

- Mother-to-child transmission of HIV

- Return for HIV care in the calendar year following pregnancy

- investigate possible contextual factors that may contribute to any identified disparities in the outcomes above, using qualitative data

- describe the experience of HIV and pregnancy in individual women's lives 


\section{Methods and design Overall study design}

A mixed methods research approach was designed to meet these objectives. The most widely accepted definition of mixed methods research is the "collecting, analysing, and mixing (of) both quantitative and qualitative data in a single study or a series of studies" [27]. The underlying assumption of mixed methods research is that it can address a research question more comprehensively than using either quantitative or qualitative methods alone. Within the field of HIV, a number of recent studies have illustrated the role of mixed methods research in engaging with the complex nature of HIV care $[28,29]$.

\section{Mixed methods model}

The present study combines epidemiological and anthropological methods, with each approach given equal weight. We used a sequential explanatory model [27] (Figure 1). The first phase was quantitative, comprising analysis of linked national surveillance data. This was followed by a qualitative phase which sought to explain and contextualise the findings from the first phase whilst highlighting other important aspects of women's experience. This qualitative phase comprised semi-structured interviews and participant observation. The study model was embedded within a framework of feminism. This theoretical lens informed the methods, analysis and interpretation throughout the study. Feminist research has a commitment to non-essentialism, which is an understanding that gender, and other social and cultural groups, are not homogeneous or concrete. By exploring differences among women, and among African women, we have attempted to move away from universal gender and ethnicity categories that dominate most epidemiological literature. Furthermore, we have used qualitative methods in an effort to engage with and document women's experiences, whilst recognising the importance of quantitative research in producing generalisable findings that may inform practice.

\section{Rationale for a mixed methods approach}

We chose a mixed methods approach as we were studying a complex biosocial phenomenon and felt that a combination of a variety of methods would enhance our understanding. Furthermore, the quantitative findings would inform our sampling and methods in the qualitative phase and the qualitative data would contextualise the quantitative results. We also felt that this approach would place the voices of women living with HIV at the centre of this study.

\section{Quantitative phase}

The quantitative phase comprised secondary analysis of epidemiological data from the National Study of HIV in Pregnancy and Childhood (NSHPC). The analysis of postnatal attendance for HIV care included data from the Survey of Prevalent Infections Diagnosed (SOPHID).

\section{The national study of HIV in pregnancy and childhood (NSHPC)}

The NSHPC, coordinated at the University College London (UCL) Institute of Child Health ( $\mathrm{ICH})$, is a population-based active surveillance study that aims to include all HIV infected women seeking antenatal care in the UK and Ireland [12]. By the end of 2011 data on approximately 15000 pregnancies since 1990 were available. Pregnancies in HIV-infected women diagnosed by the time of delivery, and infants born to infected women, are reported through two active parallel schemes managed in collaboration with the Royal College of Obstetricians and Gynaecologists and the British Paediatric

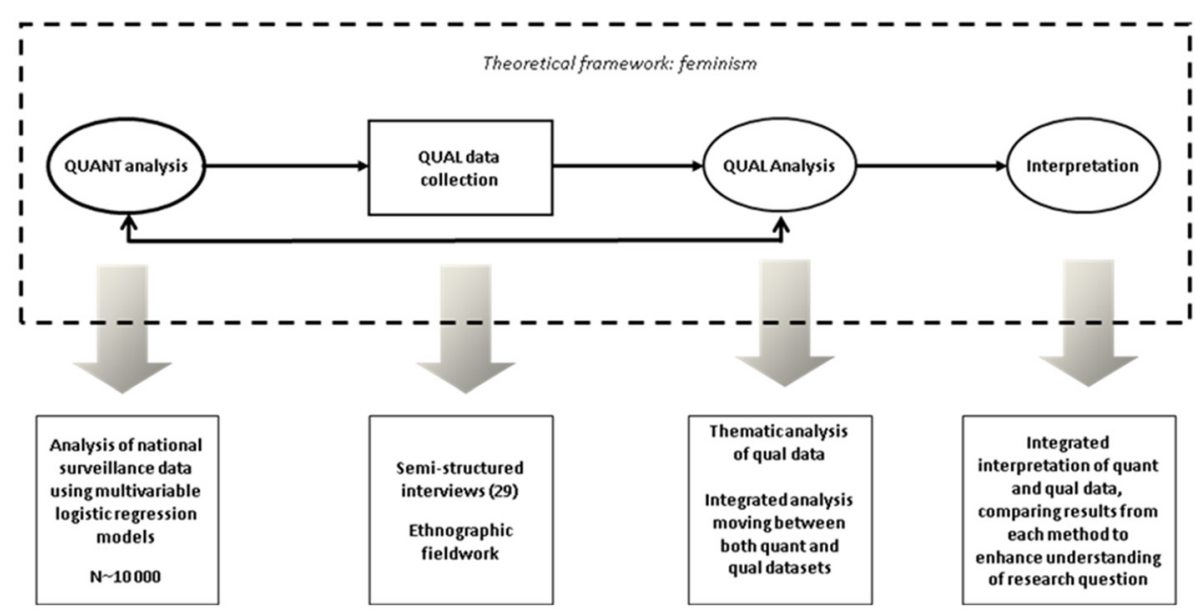

Figure 1 Mixed methods design for the study. 
Surveillance Unit [30]; full methods are described elsewhere [13]. Data collected include: maternal demographics, maternal laboratory results, clinical management of pregnancy and delivery, pregnancy outcome, and infant HIV status.

Pregnancies reported to the NSHPC were included in this study if year of delivery or estimated date of delivery (EDD) was between 1990 and 2010. Reports from Ireland were excluded, as this study focused on the UK. Reports were excluded if: the report concerned a twin or triplet who was not the first-born (to avoid duplication of information on the mother), the child was born outside the UK, or if there were no data on maternal ethnicity or country of birth (the key variables of interest).

For analyses of primary outcomes, pregnancies were included if year of delivery or EDD was 2000 or after, corresponding with wider use of ART in pregnancy and more consistency in clinical practice and monitoring than in the previous decade. Pregnancies were also excluded from these analyses if the mother was diagnosed with HIV after delivery. There were further exclusion criteria specific to each analysis and therefore numbers varied depending on the outcome examined.

\section{The survey of prevalent HIV infections diagnosed (SOPHID)}

SOPHID is an annual cross-sectional survey of all individuals aged 15 and above with diagnosed HIV infection who attend for National Health Service (NHS) HIV care in the UK within a calendar year [31]. It is coordinated by the Heath Protection Agency and was introduced in 1995. Data collected include: site of care, infection route, ethnicity and date last seen (or date of death) as well as clinical markers.

\section{Record linkage}

We created a combined dataset using NSHPC and SOPHID data to explore whether a woman returned for HIV care anywhere in England, Wales and Northern Ireland in the year following pregnancy. Women known by the NSHPC to be pregnant between 1999 and 2009 were matched to the SOPHID dataset by year of pregnancy. A hierarchical matching strategy was implemented using limited identifiers collected in both systems such as: sex; date of birth; residential information; strategic health authority; country of birth; and date of HIV diagnosis. Potential duplicate reports were identified and not included in the analysis. We excluded pregnancies in women reported from Scotland to the NSHPC or reports to SOPHID from Scotland as prior to 2008 Scottish reports to SOPHID were not linked over time, and it was therefore difficult to establish links between records in the same patient prior to 2008. Pregnancies in women known to have moved abroad during their pregnancy were also excluded. There were 9834 eligible NSHPC pregnancies between 1999 and 2009. In 8695 (88.4\%) pregnancies we were able to match the mother to a record in SOPHID.

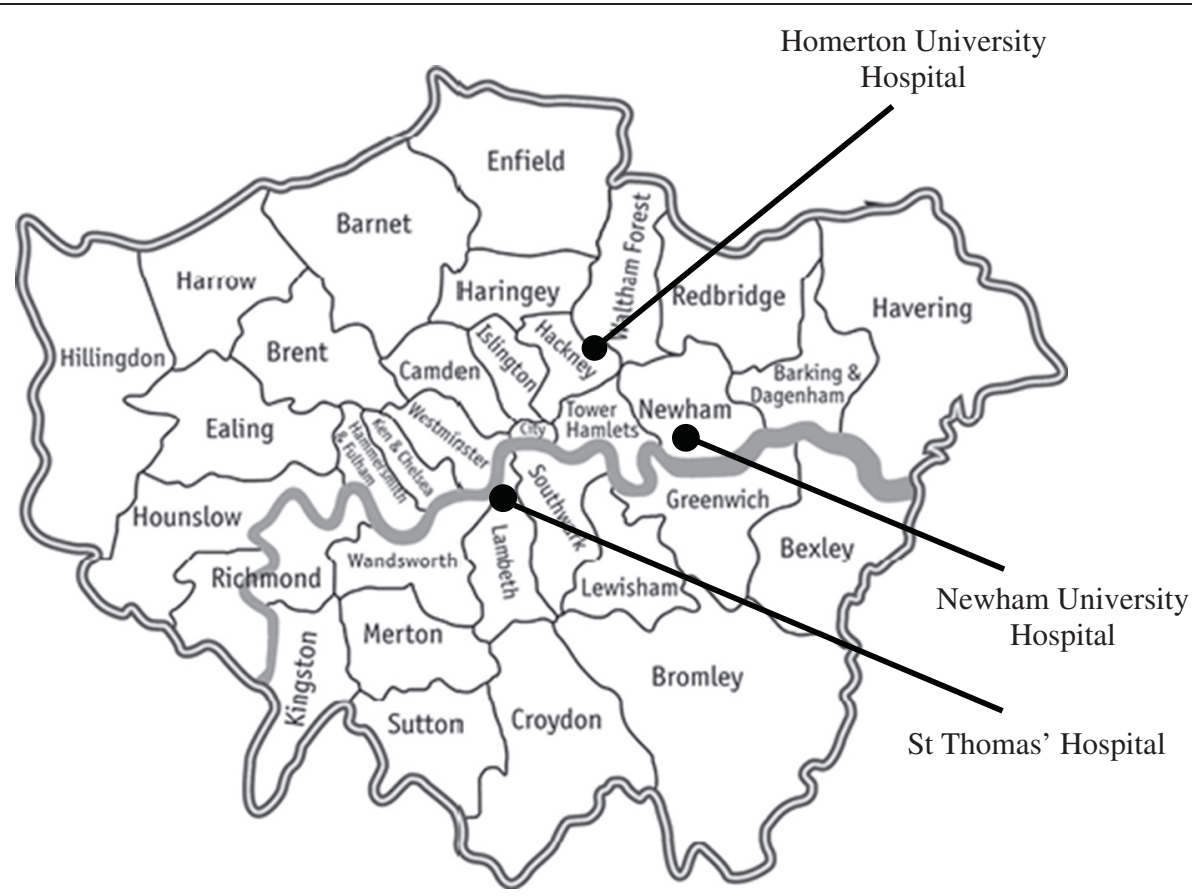

Figure 2 Map of London with NHS study sites. 


\section{Qualitative phase}

The qualitative phase of the study comprised semi-structured interviews and ethnographic fieldwork.

\section{Semi-structured interviews}

The first author conducted semi-structured interviews with pregnant African women living with HIV, healthcare providers, and staff from voluntary sector organisations.

Twenty-three pregnant women were recruited from three specialist NHS HIV antenatal clinics in London between October 2010 and October 2011 (Figure 2). These three sites are among the five hospitals reporting the largest numbers of pregnancies in HIV infected women between 2000 and 2010 (data extracted from most recent NSHPC dataset). Each centre looks after approximately 40 to 50 pregnant women living with HIV each year. They are in boroughs of great ethnic diversity, and also substantial deprivation with all three classified as among the twenty most deprived local authorities in England [32].

Healthcare professionals working at these sites identified and approached women attending for HIV antenatal care who were eligible for the study. Women were eligible if they were of black African ethnicity, were born in sub-Saharan Africa, were diagnosed with HIV and were pregnant (at any gestation). The first author was based on site during HIV antenatal clinics and was able to discuss the study further with women who were interested, providing them with an information sheet. If a woman wished to participate we found a convenient time for her to attend to be interviewed. Written informed consent was obtained prior to each interview. Face-to-face interviews $(n=20)$ were conducted in a private room in the hospital site with an interpreter present if required $(\mathrm{n}=1)$. Topics covered included experience of pregnancy; attitudes to medical interventions; psychosocial support; experience of healthcare during pregnancy; and stigma and discrimination. A minority of initial interviews $(n=3)$ were conducted by telephone due to participant preference (Figure 3). Telephone interviewing is increasingly used in health research [33] and is considered effective and especially useful in "hard to reach' populations such as mothers with young children.

A follow-up interview after birth was arranged with each woman who had been interviewed during pregnancy $(n=22)$. Serial interviews can result in the development of increased trust between researcher and participant, facilitating more open discussion [34]. Furthermore, given that the transition between pregnancy and motherhood is a dynamic time, we felt that serial interviews might better capture this changing experience. The follow-up interview occurred at a time convenient for the participant, up to one year after delivery.
Topics included experience of delivery; experience of infant feeding; support at home after delivery; and engagement with HIV services after delivery. Some of these interviews $(n=6)$ were conducted by telephone due to women's difficulty in attending for interview when caring for a newborn infant.

In total 23 women were recruited for the qualitative phase of the study over one year, the majority of them (22) recruited whilst pregnant. One participant had been approached whilst pregnant but chose to defer her interview until after delivery due to poor health. This sample size is typical of much qualitative research and allowed us to reach data saturation. Of the 22 women recruited during pregnancy, 14 (64\%) were interviewed postnatally. We were unable to contact the remaining 8 women or they declined to be interviewed again.

Interviews were recorded on a digital voice recorder where possible, unless a participant had objections to this. In these rare cases, extensive contemporaneous written notes were taken.

Initial sampling was purposive as we attempted to recruit women from a range of African regions, with a range of migration histories, and at different stages of diagnosis (Table 1). Sampling was also guided by the initial quantitative results in order to explore emerging findings. As the study progressed the sampling became theoretical as we selected potential cases to test emergent themes and theories.

The first author conducted semi-structured interviews with 4 healthcare providers involved in the care of pregnant women living with HIV. They were recruited from the collaborating NHS sites and were invited to participate by the first author. They included two consultants in HIV medicine, one HIV specialist midwife and one specialist nurse in genitourinary medicine. Interviews were also conducted with two members of staff from voluntary sector organisations with experience of supporting African women living with HIV. These participants were identified through the first author's knowledge of local voluntary sector organisations and were invited to participate by her. The purpose of interviewing health care professionals and voluntary sector workers was to elicit their experience of supporting this group of women and to identify what they saw as barriers to accessing care.

The first author also attended multidisciplinary meetings of healthcare professionals and observed some daily work at the antenatal clinics. These observations were recorded as field notes and were used to deepen and contextualise understanding of the interview data.

\section{Ethnography}

Ethnography consists of a combination of participant observation (observing activity whilst engaging directly 


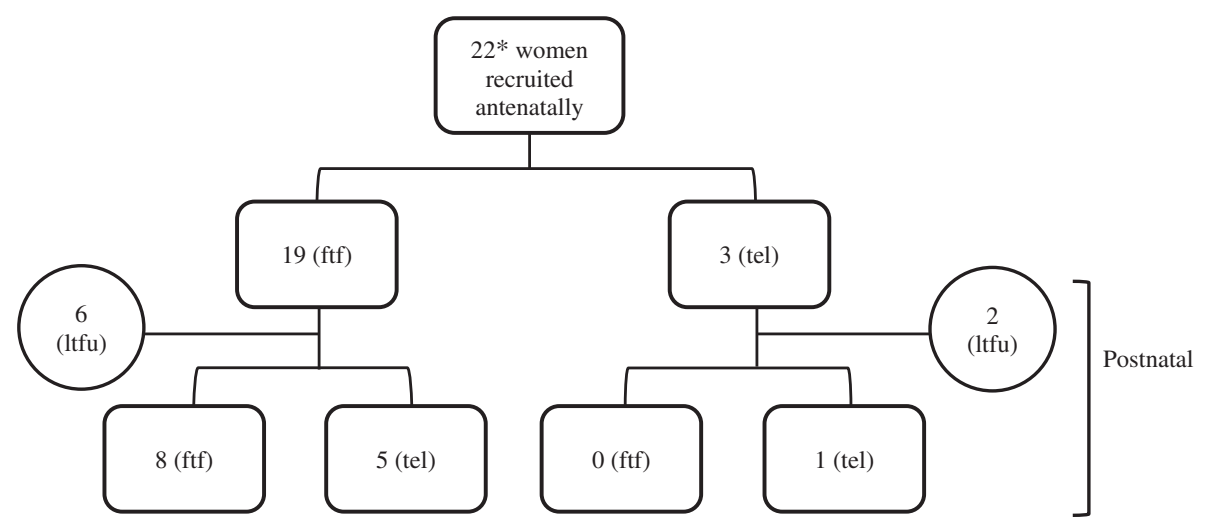

Figure 3 Semi-structured interview recruitment.

with the world being studied), informal conversation, and formal interviews, within a social group. It can contribute to a rich and multidimensional understanding of social phenomena in groups [35]. Two field sites were selected for this study.

The first site was Body \& Soul; a London-based charity that has been supporting children and families affected by HIV since 1996. A substantial number of African woman living with HIV who have experience of pregnancy attend Body \& Soul. The first author worked at Body \& Soul as a volunteer worker between April 2010 and December 2011, completing nearly 90 hours of participant observation. This fieldwork allowed the research

Table 1 NHS participant characteristics (semi-Structured Interviews)

\begin{tabular}{|c|c|}
\hline Characteristic & Number of participants $(n=23)$ \\
\hline \multicolumn{2}{|l|}{ African region of birth } \\
\hline East Africa & 9 \\
\hline West Africa & 11 \\
\hline Southern Africa & 0 \\
\hline Middle Africa & 3 \\
\hline \multicolumn{2}{|c|}{ Duration of residence in UK (years) } \\
\hline$<1$ & 1 \\
\hline $1-4$ & 4 \\
\hline $5-10$ & 12 \\
\hline$>10$ & 6 \\
\hline \multicolumn{2}{|l|}{ Immigration status* } \\
\hline Secure & 15 \\
\hline Insecure & 8 \\
\hline \multicolumn{2}{|l|}{ Diagnosis of HIV } \\
\hline Prior to current pregnancy & 20 \\
\hline During current pregnancy & 3 \\
\hline
\end{tabular}

*Secure immigration status is defined as being a UK citizen, a recognised refugee or having exceptional or indefinite leave to remain. Anyone not in these categories is defined as having insecure immigration status. team to explore the lived experience of people living with HIV, including some who were pregnant, in a nonclinical setting.

The second site was a Pentecostal church in London which has a largely diasporic Nigerian clergy and congregation. This choice of field site was guided by quantitative findings and initial interview data and this particular church was selected as it had been mentioned by a number of participants. The first author attended church services between July and September 2011, conducting nearly 40 hours of participant observation. This was complemented by watching broadcast footage of services, and conducting in-depth interviews with members of the congregation and people from the local community who are familiar with the church. The focus of this fieldwork was the role of Pentecostal faith in migrant Africans' lives and how this particular church influenced attitudes towards parenthood, health and wellbeing.

\section{Ethics}

The NSHPC has London Multi-Centre Research Ethics Committee approval (MREC/04/2/009). SOPHID does not require ethical approval as it fulfils a surveillance purpose. The HPA is registered under the Data Protection Act 1998 (registration number Z7749250) to handle data for diagnostic, public health and other purposes. The HPA is also registered under Section 251 of the Health and Social Care Act 2001 and has approval from the Patient Information Advisory Group (PIAG) to handle data for purposes that include surveillance and the control of disease, even where specific patient consent has not been given. Section 251 is renewed annually [36].

The qualitative phase of the study has ethical approval from City University Research Ethics Committee for qualitative research conducted outside NHS sites (ref $\mathrm{PhD} / 09-10 / 10)$. It also has approval from the West London Research Ethics Committee for the overall 
qualitative phase, including on behalf of the NHS sites (ref 10/10707/49).

\section{Data analysis}

This study collected both quantitative and qualitative data. Each dataset has been kept analytically distinct and has been analysed using appropriate techniques. We have moved between the datasets at the analysis stage to use findings from each analysis to generate hypotheses to be explored in the other datasets [37]. Linking will also occur at the interpretation stage, when results from the quantitative and qualitative analyses will be compared, contrasted and combined [38].

\section{Quantitative analysis}

Data were analysed using Stata 11.2 (Stata Corporation, College Station, Texas, USA). Data were summarized and examined for improbable values which were then checked against written records and amended accordingly or coded as missing. The dataset was checked for duplicate entries. Records with missing exposure or outcome data were excluded from analysis for the exposure and outcome of interest. Records with missing data on confounding variables were also dropped from final multivariable models. For analyses of trends we used the Bonferroni correction: this accounts for multiple comparisons within a group by adjusting the statistical significance level used for each test, minimising the chance of spurious positive results. For a given outcome, a Chisquare test was performed to compare pregnancies across different ethnicity, regional and migration groups. These groups were then compared for each outcome using univariable and multivariable logistic regression models to estimate odds ratios and adjusted odds ratios, with $95 \%$ confidence intervals. A priori confounders were included in final multivariable models. Other variables were included if their inclusion improved model fit. This was assessed using likelihood ratio tests, with a significance level of $p<0.05$. We used robust standard errors where appropriate to account for potential clustering at a maternal level in sequential pregnancies for some outcomes.

\section{Qualitative analysis}

A professional transcription company transcribed all interviews, with quality checks undertaken by the first author. All interview transcripts and notes made during the fieldwork at Body \& Soul were entered into NVivo 9. This qualitative data analysis software facilitates the classifying, sorting and linking of qualitative data. We are undertaking a thematic analysis of interview data, using the constant comparative method usually associated with grounded theory [39]. This is an inductive process where each transcript is read several times and sections of the text coded within the database. Coded text are then compared and linked across all the interviews if they capture a similar theme, leading to the development of broader key categories. We will pay particular attention to both the context of coded text, and also to data which does not appear to fit into the emerging thematic framework, in order to deepen our understanding. Some a priori codes will be developed from the quantitative phase, allowing us to interrogate the qualitative data to provide insight into our quantitative findings.

The first author made extensive written field notes during ethnographic fieldwork conducted at both Body \& Soul and the Pentecostal church. Ethnographic research at the church also included in-depth interviews with members of the congregation and a local Pentecostal pastor (from a different local church). We also analysed church publications and recordings of television broadcasts of church services. All ethnographic data will be hand coded, using a manual index system to organise the data. We will begin with open coding, a process where codes are identified from the data without restriction, developing broader thematic categories using the constant comparative method.

The coding of transcripts and ethnographic data will be discussed with another member of the research team to improve rigour and reliability of the analysis.

\section{Advisory group}

An advisory group was set up to provide guidance and support throughout the study. The group comprised: lay members; clinicians from the collaborating NHS centres; academics with an interest in HIV in African migrant groups; and representatives from Body \& Soul and Positively UK.

\section{Discussion}

This ongoing mixed-methods study has used epidemiological and anthropological methods to explore outcomes and experiences of pregnancy in African women living with HIV in the UK. Its particular strength is the innovative combination of quantitative and qualitative approaches, which will enable a richer understanding of this complex and multi-faceted area. Although mixed methods are increasingly used in health services research, methods such as secondary analysis of surveillance datasets and ethnography are rarely used in the context of mixed methods research. In a recent review O'Cathain et al. [40] found that the quantitative component in mixed methods health services research largely comprised primary data collection through surveys, other observation studies or intervention studies. Furthermore, semi-structured interviews were the qualitative method of choice in $80 \%$ of studies, with participant observation described in less than $1 \%$. 
The surveillance dataset used in this study was not designed for our research question and there were therefore no data on key variables such as socioeconomic and immigration status. Furthermore women interviewed in the qualitative phase may not have been included in the surveillance dataset. However, given that almost all pregnant women living with diagnosed HIV are reported to the NSHPC, it is unlikely that findings from the quantitative phase would not apply to women recruited in the qualitative phase and vice versa. The advantage of using surveillance data is the statistical power gained from such large numbers, generalisability, and the efficiency in time. The ethnographic component, although limited in duration as a result of the mixed-methods design, has resulted in a rich understanding of women's lives [35]. The findings may also allow us to inform future HIV surveillance data collection by identifying potential factors that may impact on pregnancy that are currently not collected. We feel that the methodology used in this study could be applied to other settings where complex public health questions arise.

We anticipate that the data obtained from this study will inform the provision of care to pregnant women living with HIV and the development of services that prioritise and address their needs, leading to improvements in maternal and child health.

\section{Abbreviations}

HIV: Human immunodeficiency virus; ART: Antiretroviral therapy; MSM: Men who have sex with men; MTCT: Mother-to-child transmission.

\section{Competing interests}

The authors declare that they have no competing interests.

\section{Authors' contributions}

ST conceived the study. ST designed the study with input from JE, AP and PT. AB and PT supervised the linkage of surveillance datasets. ST was responsible for qualitative data collection, and the data management and analyses of both quantitative and qualitative data. JE, AB, AP and PT provided supervision and guidance on analyses and conduct of the research. ST drafted the manuscript with input from JE, AB and PT. All authors read, revised and approved the final manuscript.

\section{Authors' information}

S Tariq is currently funded by the UK Medical Research Council (MRC) (Award number: G0701648 ID 85538) administered by City University London. The NSHPC receives core funding from the Health Protection Agency, and is located in the Centre for Paediatric Epidemiology and Biostatistics, which benefits from the MRC in its capacity as the MRC Centre of Epidemiology for Child Health. The University College of London (UCL) Institute of Child Health receives a proportion of funding from the Department of Health's National Institute for Health Research Biomedical Research Centres funding scheme. Any views expressed in this paper are those of the authors, and not necessarily those of the funders.

\section{Acknowledgements}

We would like to thank all the participants who took part in the study. We would also like to acknowledge the contribution of the NSHPC team (Janet Masters, Icina Shakes, Clare French, Claire Townsend and Hiwot Haile-Selassie) and staff from the Health Protection Agency (Valerie Delpech, Cuong Chau and Meaghan Kall). We are grateful to Body \& Soul and the Pentecostal church (which will remain anonymous) for hosting the ethnographic fieldwork. Finally, we thank the teams at the collaborating NHS sites: Guys and St Thomas'
Hospital (Annemiek De Ruiter, Claire Williams, Rozanna Issa and Alice Sharp); Homerton University Hospital (Jane Anderson, Rageshri Dhairyawan Athavan Umaipalan, Lynne Sivyour and Sifiso Mguni); and Newham University Hospital (Heather Noble, Rebecca O'Connell, Lisa Welcland, Rhonda Reddington and Cheryl Tawana).

\section{Author details}

${ }^{1}$ School of Health Sciences, City University London, 20 Bartholomew Close, London EC1A 7QN, United Kingdom. ${ }^{2}$ Department of Anthropology, University College London, 14 Taviton Street, London WC1H OBW, United Kingdom. ${ }^{3} \mathrm{MRC}$ Centre of Epidemiology for Child Health, UCL Institute of Child Health, 30 Guilford St, London WC1N 1EH, United Kingdom. ${ }^{4}$ HIV \& STI Department, Health Protection Services - Colindale, Health Protection Agency, 61 Colindale Avenue, London NW9 5EQ, United Kingdom.

Received: 6 July 2012 Accepted: 18 July 2012

Published: 2 August 2012

\section{References}

1. Health Protection Agency: HIV in the United Kingdom: 2011 Report. London: Health Protection Agency; 2011:2011.

2. Burns FM, Fakoya AO, Copas AJ, French PD: Africans in London continue to present with advanced HIV disease in the era of highly active antiretroviral therapy. AIDS 2001, 15:2453-2455.

3. Burns FM, Imrie JY, Nazroo J, Johnson AM, Fenton KA: Why the(y) wait? Key informant understandings of factors contributing to late presentation and poor utilization of HIV health and social care services by African migrants in Britain. AIDS Care 2007, 19:102-108.

4. Thomas F, Aggleton P, Anderson J: "If I cannot access services, then there is no reason for me to test": the impacts of health service charges on HIV testing and treatment amongst migrants in England. AIDS Care: Psychological and Socio-medical Aspects of AIDS/HIV 2010, 22:526-531.

5. Rice BD, Delpech VC, Chadborn TR, Elford J: Loss to Follow-Up Among Adults Attending Human Immunodeficiency Virus Services in England, Wales, and Northern Ireland. Sex Transm Dis 2011, 38:685-690.

6. Gerver S, Chadborn T, Ibrahim F, Vatsa B, Delpech V, Easterbrook P: High rate of loss to clinical follow up among African HIV-infected patients attending a London clinic: a retrospective analysis of a clinical cohort. J Int AIDS Soc 2010, 13:29.

7. Weatherburn P, Ssanyu-Sseruma W, Hickson F, McLean S, Reid D: Project Nasah: An investigation into the HIV treatment information and other needs of African people with HIV resident in England. London: Sigma Research; 2003.

8. Ibrahim F, Anderson J, Bukutu C, Elford J: Social and economic hardship among people living with HIV in London. HIV Med 2008, 9:616-624.

9. Doyal $L$ : Challenges in researching life with HIV/AIDS: an intersectional analysis of black African migrants in London. Cult Heal Sex 2009, 11:173188.

10. Allan CL, Clarke J: Are HIV/AIDS services in Leeds, UK, able to meet the needs of asylum seekers? Public Health 2005, 119:305-311.

11. Cherfas L: Negotiating access and culture: Organizational responses to the healthcare needs of refugees and asylum seekers living with HIV in the UK. Oxford: Refugee Studies Centre, University of Oxford; 2006.

12. National Study of HIV in Pregnancy and Childhood, Latest summary data. http://www.nshpc.ucl.ac.uk/.

13. Townsend CL, Cortina-Borja M, Peckham CS, Tookey PA: Trends in management and outcome of pregnancies in HIV-infected women in the UK and Ireland, 1990-2006. BJOG 2008, 115:1078-1086.

14. Duong $T$, Ades AE, Gibb DM, Tookey PA, Masters J: Vertical transmission rates for HIV in the British Isles: estimates based on surveillance data. BMJ 1999, 319:1227-1229.

15. Townsend CL, Cortina-Borja M, Peckham CS, de Ruiter A, Lyall H, Tookey PA: Low rates of mother-to-child transmission of HIV following effective pregnancy interventions in the United Kingdom and Ireland, 2000-2006. AIDS 2008, 22:973-981.

16. Briand N, Mandelbrot L, Blanche S, Tubiana R, Faye A, Dollfus C, Chenadec $J L$, Benhammou V, Rouzioux C, Warszawski J, ANRS French Perinatal Cohort (ANRS EPF-CO-01): Previous antiretroviral therapy for prevention of mother-to-child transmission of HIV does not hamper the initial response to PI-based multitherapy during subsequent pregnancy. $J$ Acquir Immune Defic Syndr 2011, 57:126-135. 
17. Tariq S, Townsend CL, Cortina-Borja M, Duong T, Elford J, Thorne C, Tookey PA: Use of zidovudine-sparing HAART in pregnant HIV-infected women in Europe: 2000-2009. J Acquir Immune Defic Syndr 2011, 57:326-333.

18. Katz IT, Shapiro R, Li D, Govindarajulu U, Thompson B, Watts DH, Hughes MD, Tuomala R: Risk Factors for Detectable HIV-1 RNA at Delivery Among Women Receiving Highly Active Antiretroviral Therapy in the Women and Infants Transmission Study. J Acquir Immune DeficSyndr 2010, 54:27-34.

19. Saulsbury N, Forsyth SF, Thorburn D, Baruah J, Whyte P: Patterns of attendance post-delivery for antenatally diagnosed HIV positive women. HIV Med 2004, 5(Suppl. 2):14-45.

20. Carter N: The social impact of HIV in pregnancy. London School of Economics: MSc thesis; 2009

21. Naftalin C, Moore E, Hadley W, Perry N, Gilleece Y: A qualitative study to explore factors influencing the beliefs and behaviour of HIV-positive pregnant women. HIV Med 2010, 11(Suppl. 1):1-119.

22. Wilson S: 'When you have children, you're obliged to live': motherhood, chronic illness and biographical disruption. Sociology of Health \& Illness 2007, 29:610-626.

23. Conaty SJ, Cassell JA, Harrisson U, Whyte P, Sherr L, Fox Z: Women who decline antenatal screening for HIV infection in the era of universal testing: results of an audit of uptake in three London hospitals. J Public Health (Oxf) 2005, 27:114-117.

24. French C, Cortina-Borja M, Thorne C, Tookey P: Incidence, patterns, and predictors of repeat pregnancies among HIV-infected women in the United Kingdom and Ireland, 1990-2009. J Acquir Immune Defic Syndr 2012, 59:287-293.

25. Patel D, Cortina-Borja M, Thorne C, Newell ML: Time to undetectable viral load after highly active antiretroviral therapy initiation among HIVinfected pregnant women. Clin Infect Dis 2007, 44:1647-1656.

26. Jasseron C, Mandelbrot L, Tubiana R, Teglas JP, Faye A, Dollfus C, Le Chenadec J, Rouzioux C, Blanche S, Warszawski J: Prevention of mother-tochild HIV transmission: similar access for sub-Sahara African immigrants and for French women? AIDS 2008, 22:1503-1511.

27. Creswell JW, Plano Clark VL: Designing and conducting mixed methods research. London: Sage Publications Ltd; 2007.

28. Chow MYK, Quine S, Li M: The benefits of using a mixed methods approach "quantitative with qualitative" to identify client satisfaction and unmet needs in an HIV healthcare centre. AIDS Care: Psychological and Socio-medical Aspects of AIDS/HIV 2010, 22:491-498.

29. Laher F, Cescon A, Lazarus E, Kaida A, Makongoza M, Hogg RS, Soon CN, Miller CL, Gray G: Conversations With Mothers: Exploring Reasons for Prevention of Mother-to-Child Transmission (PMTCT) Failures in the Era of Programmatic Scale-Up in Soweto. AIDS Behav 2012, 16:91-98.

30. Nicoll A, Lynn R, Rahi J, Verity C, Haines L: Public health outputs from the British Paediatric Surveillance Unit and similar clinician-based systems. R Soc Med 2000, 93:580-585.

31. Smith RD, Delpech VC, Brown AE, Rice BD: HIV transmission and high rates of late diagnoses among adults aged 50 years and over. AIDS 2010 24:2109-2115.

32. Department for communities and local government: The English Indices of Deprivation 2010. London: Department for communities and local government; 2011.

33. Musselwhite $\mathrm{K}$, Cuff L, McGregor L, King KM: The telephone interview is an effective method of data collection in clinical nursing research: A discussion paper. Int J Nurs Stud 2007, 44:1064-1070.

34. Murray SA, Kendall M, Carduff E, Worth A, Harris FM, Lloyd A, Cavers D, Grant L, Sheikh A: Use of serial qualitative interviews to understand patients' evolving experiences and needs. BMJ 2009, 339:b3702.

35. Reeves S, Kuper A, Hodges BD: Qualitative research methodologies: ethnography. BMJ 2008, 337:a1020

36. Health Protection Agency, Surveillance and confidentiality.: ; http://www.hpa. org.uk/ProductsServices/InfectiousDiseases/ServicesActivities/Surveillance/ SourcesOfSurveillanceData/.

37. Moran-Ellis J, Alexander V, Cronin A, Dickinson M, Fielding J, Sleney J, Thomas $\mathrm{H}$ : Triangulation and integration: processes, claims and implications. Qual Res 2006, 6:45-59.

38. Sandelowski M: Combining qualitative and quantitative sampling, data collection, and analysis techniques in mixed-method studies. Res Nurs Health 2000, 23:246-255.

39. Pope C, Ziebland S, Mays N: Qualitative research in health care: Analysing qualitative data. BMJ 2000, 320:114-116.
40. O'Cathain A, Murphy E, Nicholl J: Why, and how, mixed methods research is undertaken in health services research in England: a mixed methods study. BMC Heal Serv Res 2007, 7:85.

doi:10.1186/1471-2458-12-596

Cite this article as: Tariq et al:: The impact of African ethnicity and migration on pregnancy in women living with HIV in the UK: design and methods. BMC Public Health 2012 12:596.

\section{Submit your next manuscript to BioMed Central and take full advantage of:}

- Convenient online submission

- Thorough peer review

- No space constraints or color figure charges

- Immediate publication on acceptance

- Inclusion in PubMed, CAS, Scopus and Google Scholar

- Research which is freely available for redistribution

Submit your manuscript at www.biomedcentral.com/submit
C Biomed Central 